\title{
Journal of Materials Science \\ Silicone dielectric elastomers based on radical crosslinked high molecular weight polydimethylsiloxane co-filled with silica and barium titanate \\ --Manuscript Draft--
}

Manuscript Number:

Full Title:

Article Type:

Keywords:

Corresponding Author:
JMSC-D-15-01786R1

Silicone dielectric elastomers based on radical crosslinked high molecular weight polydimethylsiloxane co-filled with silica and barium titanate

Manuscript (Regular Article)

dielectric elastomers; silicones; Composites; barium titanate; silica; energy harvesting

Maria Cazacu, senior researcher

Iasi, ROMANIA

\section{Corresponding Author Secondary}

Information:

Corresponding Author's Institution:

\section{Corresponding Author's Secondary} Institution:

\section{First Author:}

First Author Secondary Information:

Order of Authors:

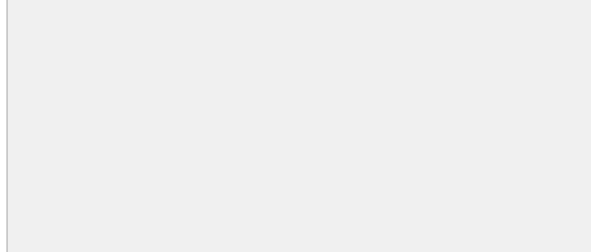

\section{Order of Authors Secondary Information:}

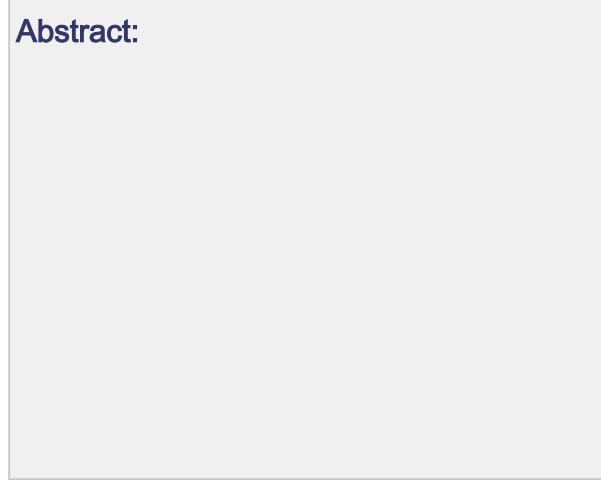

Funding Information:

\section{Adrian Bele}

Adrian Bele

George Stiubianu

Cristian-Dragos Varganici

Mircea Ignat

Maria Cazacu, senior researcher

A strategy, consisting in the use in tandem of two active fillers in different ratios with complementary effects: silica mainly as a reinforcing agent and barium titanate as dielectric permittivity enhancer, was approached to optimize the electromechanical properties of the silicone elastomers. A high molecular mass polydimethylsiloxane- $\alpha, \omega-$ diol $(\mathrm{Mw}=642000 \mathrm{~g} \cdot \mathrm{mol}-1)$ was used as a matrix to prepare silicone composites, which further were processed as films and crosslinked at high temperature. The morphology, thermal and moisture behaviour of the films were studied by adequate techniques. The mechanical properties were estimated on the basis of normal and cyclic stress-strain curves. Dielectric spectra were recorded in the frequency range $1-106 \mathrm{~Hz}$ at normal temperature. The voltages generated by a mechanical impulse created by falling of a metal ball of $7.1 \mathrm{~g}$ from a height of one hundred millimetres on the surface of the films placed between two electrodes ranged between 28.4 and $157.3 \mathrm{~V} / \mathrm{mm}$.

\begin{tabular}{l|l|}
$\begin{array}{l}\text { 7th Framework Programme of European } \\
\text { Community } \\
(309139)\end{array}$ & Dr. Maria Cazacu \\
\hline $\begin{array}{l}\text { Romanian National Authority for Scientific } \\
\text { Research, CNCS-UEFISCDI } \\
(205 E U)\end{array}$ & Dr. Maria Cazacu \\
\hline $\begin{array}{l}\text { Romanian National Authority for Scientific } \\
\text { Research, CNCS-UEFISCDI } \\
\text { (PN-II-ID-PCCE-2011-2-0028) }\end{array}$ & Cristian-Dragos Varganici \\
\hline
\end{tabular}




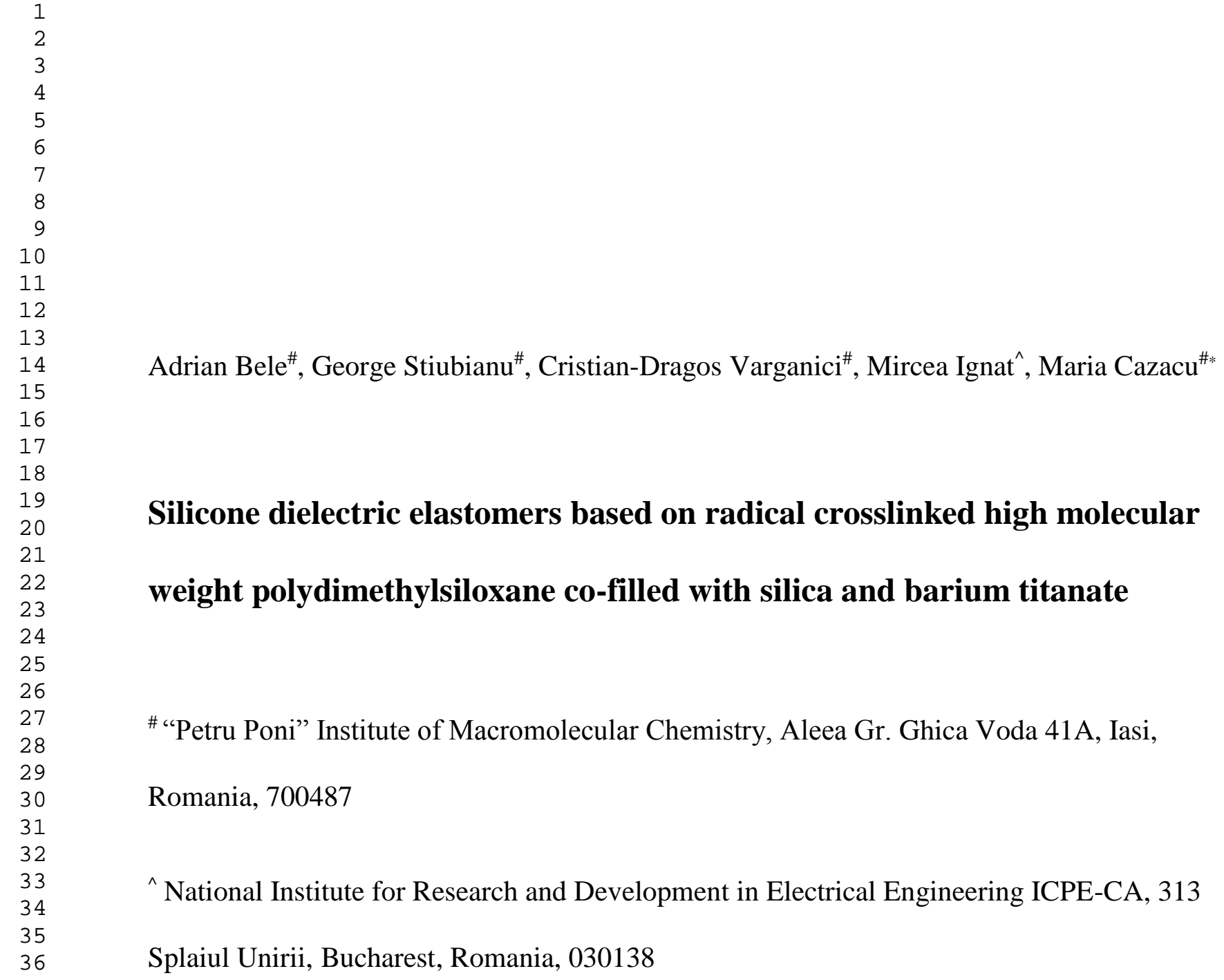

Adrian Bele ${ }^{\#}$, George Stiubianu*, Cristian-Dragos Varganici ${ }^{\#}$, Mircea Ignat^, Maria Cazacu ${ }^{\# *}$

\section{Silicone dielectric elastomers based on radical crosslinked high molecular weight polydimethylsiloxane co-filled with silica and barium titanate}

\# “Petru Poni” Institute of Macromolecular Chemistry, Aleea Gr. Ghica Voda 41A, Iasi,

Romania, 700487

${ }^{\wedge}$ National Institute for Research and Development in Electrical Engineering ICPE-CA, 313

Splaiul Unirii, Bucharest, Romania, 030138

\footnotetext{
* To whom correspondence will be addressed, e-mail: mcazacu@icmpp.ro
} 


\section{Abstract}

A strategy, consisting in the use in tandem of two active fillers in different ratios with complementary effects: silica mainly as a reinforcing agent and barium titanate as dielectric permittivity enhancer, was approached to optimize the electromechanical properties of the silicone elastomers. A high molecular mass polydimethylsiloxane- $\alpha, \omega$-diol $\left(\mathrm{Mw}=642000 \mathrm{~g} \cdot \mathrm{mol}^{-}\right.$

${ }^{1}$ ) was used as a matrix to prepare silicone composites, which further were processed as films and crosslinked at high temperature. The morphology, thermal and moisture behaviour of the films were studied by adequate techniques. The mechanical properties were estimated on the basis of normal and cyclic stress-strain curves. Dielectric spectra were recorded in the frequency range 1$10^{6} \mathrm{~Hz}$ at normal temperature. The voltages generated by a mechanical impulse created by falling of a metal ball of $7.1 \mathrm{~g}$ from a height of one hundred millimetres on the surface of the films placed between two electrodes ranged between 28.4 and $157.3 \mathrm{~V} / \mathrm{mm}$.

Keywords: dielectric elastomers; silicones; composites; barium titanate; silica; energy harvesting 


\section{Introduction}

Energy harvesting technologies aiming the conversion of different energy forms (light, thermal, mechanical, etc.) [1] from the natural sources such as wind, waves, or animal movements into electrical energy is attracting a high interest in the scientific community in special in the last twenty years [2,3]. One way to convert the mechanical energy into electrical one is to use high reversible deformability of the dielectric elastomers. Among this class of materials, silicones attract great interest because of their high elasticity and weather resistance [4-8]. A drawback of silicones is their low dielectric permittivity (in the range 2.5-3.0), many studies thus aiming to improve this parameter and maintaining good mechanical properties. The unique molecular structure and chemistry of the silicone polymers permit their formulations that meet to a specific application. Different strategies have been used to improve the dielectric properties [9], but the most promising one is incorporation of filler particles with high dielectric permittivity, such as ceramic fillers (e.g., barium titanate, titanium dioxide, calcium copper titanium oxide, lead zirconate, etc.) [10-14]. The dielectric relaxation of the crystallites embedded into the polymer matrices was studied $[15,16]$ and it was established the principal role of the interface states on the border polymer-crystallites in defining the corresponding dielectric features. Barium titanate, a ferroelectric crystal with high dielectric strength, is widely used for this purpose [17-20]. The effect of $\mathrm{BaTiO}_{3}$ nanoparticles on electrical and mechanical properties are extensively studied and found that dielectric constant of nanocomposites significantly increases with the increase in $\mathrm{BaTiO}_{3}$ concentration whereas volume resistivity decreases continuously [21]. However, while the thermal stability of the composites in which it is incorporated increases, the mechanical properties, i.e. tensile strength and elongation at break are worsened as BT content increase due to no reinforcing nature of BT [22]. On the other hand, the effective reinforcing effect 
(increasing in tensile strength, tear resistance, compression set, and good dynamic properties besides anti-aging and anti-friction) of the nano-silica on the silicone rubber is well-known [23, 24]. Depending on the silica content, the silicones strength could be significantly increased. However, by the addition of silica as filler, an increase in stiffness, undesired in electromechanical application, occurs simultaneous with resistance to fracture. Therefore, a compromise must be made between these two features.

Continuing our efforts to obtain silicone elastomers with optimized electro-mechanical properties [11, 25-28], in this paper we addressed the working strategy consisting in the original combination of two active fillers with complementary effects: silica, as a reinforcing filler and barium titanate, both from commercial sources, to increase the dielectric permittivity of the composites obtained. In addition, the originality of our approach consists in the using as a matrix of a polydimethylsiloxane of high molecular weight $\left(\mathrm{Mw}=642000 \mathrm{~g} \cdot \mathrm{mol}^{-1}\right)$ and its curring by radical mechanism, which takes place at high temperature and pressure. The cross-linking pattern is different from that used in the majority of cases reported in the literature to stabilize the dielectric silicone elastomers for which, in general commercial silicone kits with vulcanization by condensation of the chain ends with a tri- or tetrafunctional crosslinking agent are used $[5,25$, $29,30]$. The system reported here rather resembles the curing by hydrosilylation but which is applicable only in case of relatively low molecular weight polysiloxanes, more flexible, to ensure access to each other functional groups ( $\mathrm{Si}-\mathrm{H}$ and $\left.\mathrm{Si}-\mathrm{CH}=\mathrm{CH}_{2}\right)[27,31,32]$. The films obtained by us are robust, easy to handle and use in tougher conditions. Also, an original setup was used to roughly evaluate energy output capacity based on direct piezoelectric effect without previous polarization. The effect of filler`s presence and their amounts embedded within a polysiloxane matrix of high molecular weight on the mechanical properties and dielectric behavior were 
studied. Also, preliminary estimations of the ability of the resulted materials to convert mechanical energy into electric one were made on a homemade set up.

\section{Materials and Methods}

\subsection{Materials}

The polymeric matrix, polydimethylsiloxane- $\alpha, \omega-$ diol (PDMS), was obtained by bulk polymerization of octamethylcyclotetrasiloxane catalyzed by $\mathrm{H}_{2} \mathrm{SO}_{4}$, at room temperature, according to procedure described in ref. [33]. A small percent of vinyl-substituted cycle (3 wt $\%$ heptamethylvinylciyclotetrasiloxane, $\left(\left[\left(\mathrm{CH}_{3}\right)_{2} \mathrm{SiO}\right]_{3}\left[\mathrm{C}_{2} \mathrm{H}_{3}\left(\mathrm{CH}_{3}\right) \mathrm{SiO}\right]\right)$, was added. The polymer was purified by repeated washing with slight alkaline solution and then with water, until a neutral $\mathrm{pH}$. Then, the polymer was devolatilized in vacuum at $180{ }^{\circ} \mathrm{C}$ to remove water and low molecular weight siloxanes. The molecular mass, as was evaluated by Gel Permeation Chromatography by using chloroform as eluent, was Mw=642000 $\mathrm{g} \cdot \mathrm{mol}^{-1}\left(\mathrm{Mn}=438000 \mathrm{~g} \cdot \mathrm{mol}^{-1}\right)$, $\mathrm{d}=1.00 \mathrm{~g} \cdot \mathrm{cm}^{-3}$, dielectric permittivity $\varepsilon^{\prime}=2.9$. Fumed silica, Aerosil 380 (Degussa), with $100 \%$ purity, specific surface area $380 \mathrm{~m}^{2} / \mathrm{g}$, particle diameter $3-15 \mathrm{~nm}, \mathrm{~d}=2.2 \mathrm{~g} \cdot \mathrm{cm}^{-3}$, tapped density around $50 \mathrm{~g} \cdot 1^{-1}$, dielectric permittivity $\varepsilon^{\prime}=3.9$ and barium titanate, $\mathrm{BaTiO}_{3}$, (Fluka AG), BT, with m.p. $1625{ }^{\circ} \mathrm{C}$, particle size $<3 \mu \mathrm{m}, \mathrm{d}=6.08 \mathrm{~g} \cdot \mathrm{cm}^{-3}$, dielectric permittivity $\varepsilon^{\prime}=1700$ at room temperature were dried in vacuum at $100{ }^{\circ} \mathrm{C}$ and hydrophobized by treatment with dimethylcyclosiloxanes mixture in vapour state. 2,4-Dichlorobenzoyl peroxide, paste $50 \%$ in silicone oil, having a critical temperature: $60-70{ }^{\circ} \mathrm{C}$ and set-cure temperature in the range $115-$ $150^{\circ} \mathrm{C}$. 


\subsection{Measurements}

Gel permeation chromatographic analysis, GPC, was carried out on a PL-EMD 950 Evaporative Mass Detector instrument by using $\mathrm{CHCl}_{3}$ as eluent, after calibration with standard polystyrene samples. The obtained thick films were cryo-fractured and the cross-section surface was examined with an Environmental Scanning Electron Microscope (ESEM) type Quanta 200, operating at $30 \mathrm{kV}$ with secondary electrons in low vacuum mode. Stress-strain measurements were performed on TIRA test 2161 apparatus, Maschinenbau GmbH Ravenstein, Germany, on dumbbell-shaped cut samples with dimensions of 50x8.5x4 mm. Measurements were run at an extension rate of $20 \mathrm{~mm} / \mathrm{min}$, at room temperature. All samples were measured three times and the averages of the obtained values were taken into consideration. The acquired data were processed with MatLab software. Cyclic tensile stress tests were performed on the similar samples between 2 and $100 \%$ strain. The maximum force applied was tensile stress value as determined by previous test. Five stretch-recovery cycles were registered. The stationary time at minimum and maximum applied stress was $5 \mathrm{~s}$. Novocontrol setup (Broadband dielectric spectrometer Concept 40, Germany), integrating an ALPHA frequency response analyzer and a Quatro temperature control system, was used to investigate the dielectric properties of the polymer composites over a broad frequencies window, $10^{0}-10^{6} \mathrm{~Hz}$, at room temperature. The bias voltage applied across the sample was $1.0 \mathrm{~V}$. Samples having thickness in the $0.5-1 \mathrm{~mm}$ range were placed between gold plated round electrodes, the upper electrode having a $20 \mathrm{~mm}$ diameter. Differential Scanning Calorimetry measurements, DSC, were conducted on a DSC 200 F3 Maia (Netzsch, Germany). A mass of $10 \mathrm{mg}$ from each sample was heated in pressed and pierced aluminum crucibles from -150 to $50{ }^{\circ} \mathrm{C}$ at a heating rate/cooling rate of $10 /-10{ }^{\circ} \mathrm{C} \mathrm{min}^{-1}$ and in nitrogen as inert atmosphere at a flow rate of $50 \mathrm{~mL} \mathrm{~min}^{-1}$. The temperature against heat 
flow was recorded. The baseline was obtained by scanning the temperature domain of the experiments with an empty pan. The enthalpy was calibrated with indium according to standard procedures. Water vapors sorption capacity of the film samples was measured by using the fully automated gravimetric analyzer IGAsorp supplied by Hiden Analytical, Warrington (UK). The measurements were performed at room temperature $\left(\sim 25^{\circ} \mathrm{C}\right)$ in the $0-90 \%$ relative humidity range (Figure 3S). A step of humidity change of $10 \mathrm{wt} \%$ and pre-established equilibrium time between 10 and 30 minutes were used. The samples were dried previously in flowing nitrogen (250 $\mathrm{mL} / \mathrm{min})$ until a constant weight was achieved. An ultrasensitive microbalance measures the weight change as the humidity is modified in the sample chamber at a constant regulated temperature. The measurement system is controlled by a IGASORP Windows ${ }^{\mathrm{TM}}$ based software package. Harvesting experiments (voltage recording) were performed by using a memory oscilloscope Tektronix DPO 4032 (350MHz, 2.5GS/s), as we already described in ref. [11, 23].

\subsection{Preparation of the composites and films formation}

Previously hydrophobized silica nanoparticles and barium titanate were stepwise incorporated in small portions within the PDMS by mechanical mixing in a Yanke - Kunkel laboratory mixer equipped with double palettes and cooling mantle in different percentages, according to Table 1. The homogenization was finalized on a rampart, where the crosslinking catalyst $(2 \mathrm{wt} \% 2,4-$ dichlorobenzoyl peroxide) was also added [33]. To obtain crosslinked films, small amounts of each mixture $(\sim 10 \mathrm{~g})$ were put as a round blob of material inside frame $(1 \times 70 \times 70 \mathrm{~mm})$ mounted between two stainless steel plates $(1 \times 100 \times 100 \mathrm{~mm})$ and pressed with a manual press, after that this assembly was heated at $120^{\circ} \mathrm{C}$ for $1 \mathrm{~h}$ when crosslinking occurs. Then, the films peeled off from the substrate were post-curred by maintaining for $10 \mathrm{~h}$ at $150{ }^{\circ} \mathrm{C}$ in air stream for 
devolatilization. These films were used to investigate some of the properties of interest for the target application.

Table 1. Recipes to obtain desired elastomers (added catalyst: 2 wt $\%$ 2,4-dichlorobenzoyl peroxide)

\begin{tabular}{lcc}
\hline Sample & Silica, wt\% & Barium Titanate, wt \% \\
\hline S0B0 & $0 \%$ & 0 \\
\hline S10 B0 & \multirow{2}{*}{$10 \%$} & 0 \\
\cline { 1 - 1 } S10 B5 & & 5 \\
\cline { 1 - 1 } S10 B15 & & 15 \\
\hline S15 B0 & $15 \%$ & 0 \\
\hline S15 B5 & & 5 \\
\hline S15 B15 & & 15 \\
\hline S30 B0 & & 0 \\
\hline S30 B5 & $30 \%$ & 5 \\
\hline S30 B15 & & 5 \\
\hline
\end{tabular}

\section{Results and discussion}

A polydimethylsiloxane- $\alpha, \omega$-diol of high molecular mass $\left(\mathrm{Mw}=642000 \mathrm{~g} \cdot \mathrm{mol}^{-1}\right)$ was used as a matrix to prepare silicone composites. Two fillers, silica and barium titanate, were incorporated in different ratios (Table 1) within the polymer to improve its properties, each of them having a specific role. Thus, while the silica adding aims to improve the mechanical properties, the ceramic material should lead to increased dielectric permittivity. Both fillers were previously surface hydrophobized by treating with dimethylcyclosiloxanes mixture in vapour state. The composites formulated with different percentages of each filler were processed as films with 
dimensions of 70x70x1 mm, and stabilized by radical curing initiated by 2,4-dichlorobenzoyl peroxide at $120^{\circ} \mathrm{C}$ in a press. At high temperature, the peroxide decomposes to form free radicals that attack preferably vinyl groups, these continuing free radical chain reactions. In such conditions, the crosslinking occurs by the formation of the alkylene (ethylene, propylene) interchain bridges along the siloxane backbone [34] (Figure 1).

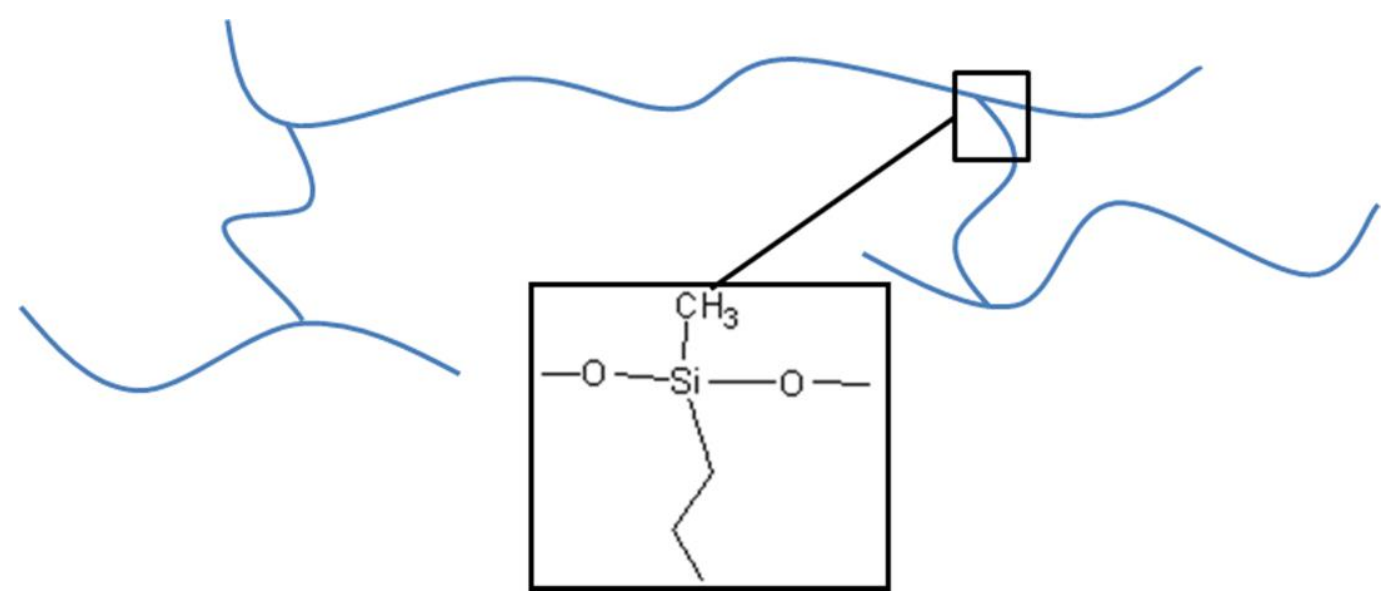

Figure 1. Chain crosslinking pattern.

\subsection{Morphology}

The distribution of the fillers within the polymeric matrix was appreciated by SEM examination of the cryo-fractured cross-section surface. The SEM images of the samples filled with silica only, taken with the resolution according to Figure 2, reveal a good dispersion of these nanoparticles not being identified individual or agglomerated silica nanoparticles neither at 10 nor at $30 \mathrm{wt} \%$ content (sample S10B0 - Figure 2d, S15B0 - Figure 2g and S30B0 - Figure 2j). Instead, in the samples in which barium titanate was incorporated, aggregates thereof with large dimensional dispersion from a few micrometres corresponding to ex situ dimensions of the barium titanate (Figure 2a,b) to 50-60 $\mu \mathrm{m}$ (Figure 2f-1) can be seen. It is presumed that the 
aggregation occurs during the hydrophobization treatment due to the high incompatibility between the strong hydrophobic dimethylcyclosiloxane and hydrophilic barium titanate, which is not soluble in water but disperses well in it. As a result, there is a natural tendency of the particles to agglomerate at the expense of their coverage with a hydrophobic coating. It seems that this method is not optimal for the hydrophobization of barium titanate. It is assumed that the use of a silane coupling agent such as alkyltrialkoxysilane or hexamethyldisilazane would be more appropriate in order to maintain a good dispersion of the polar filler within a nonpolar matrix. 

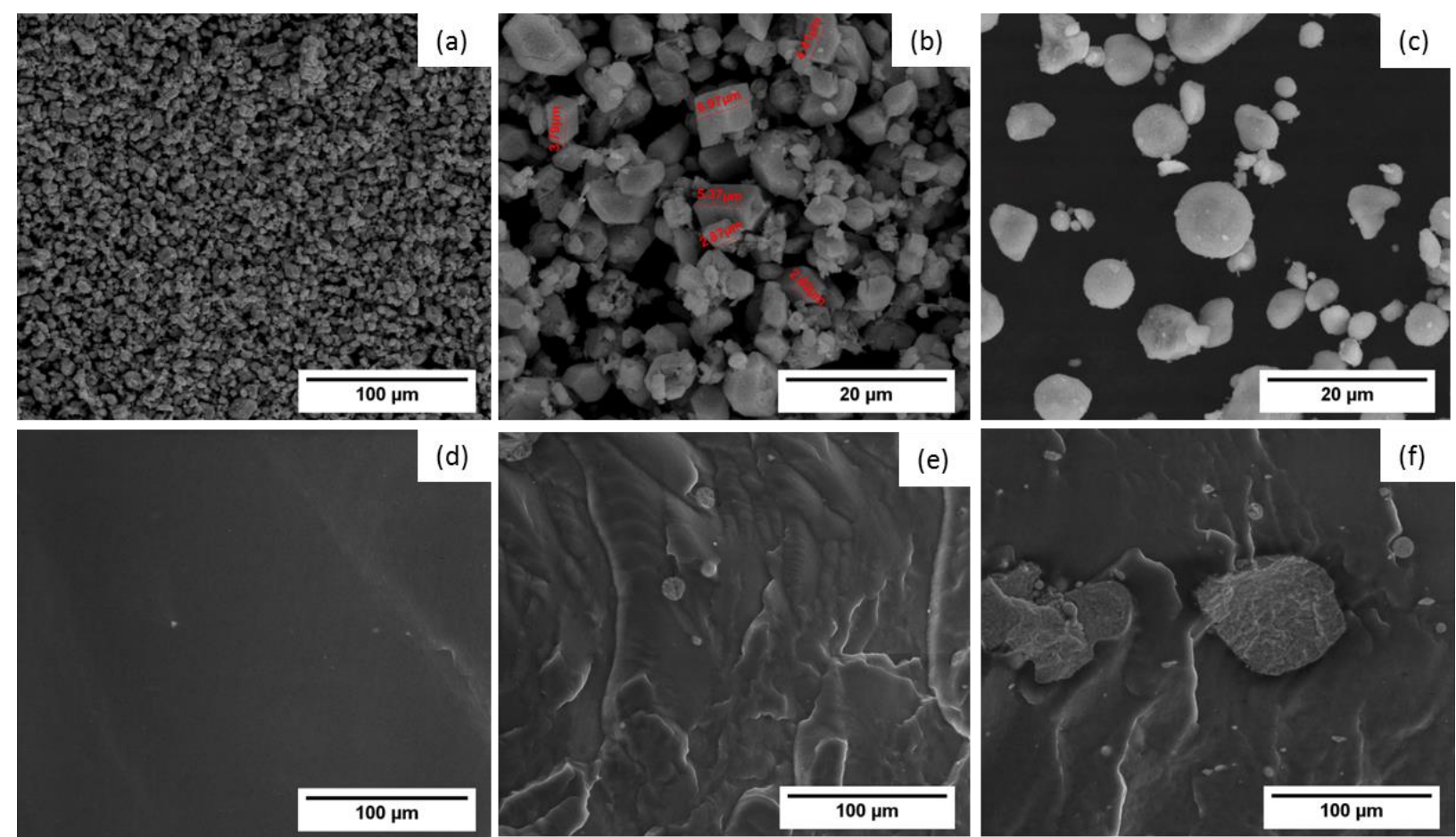

e)
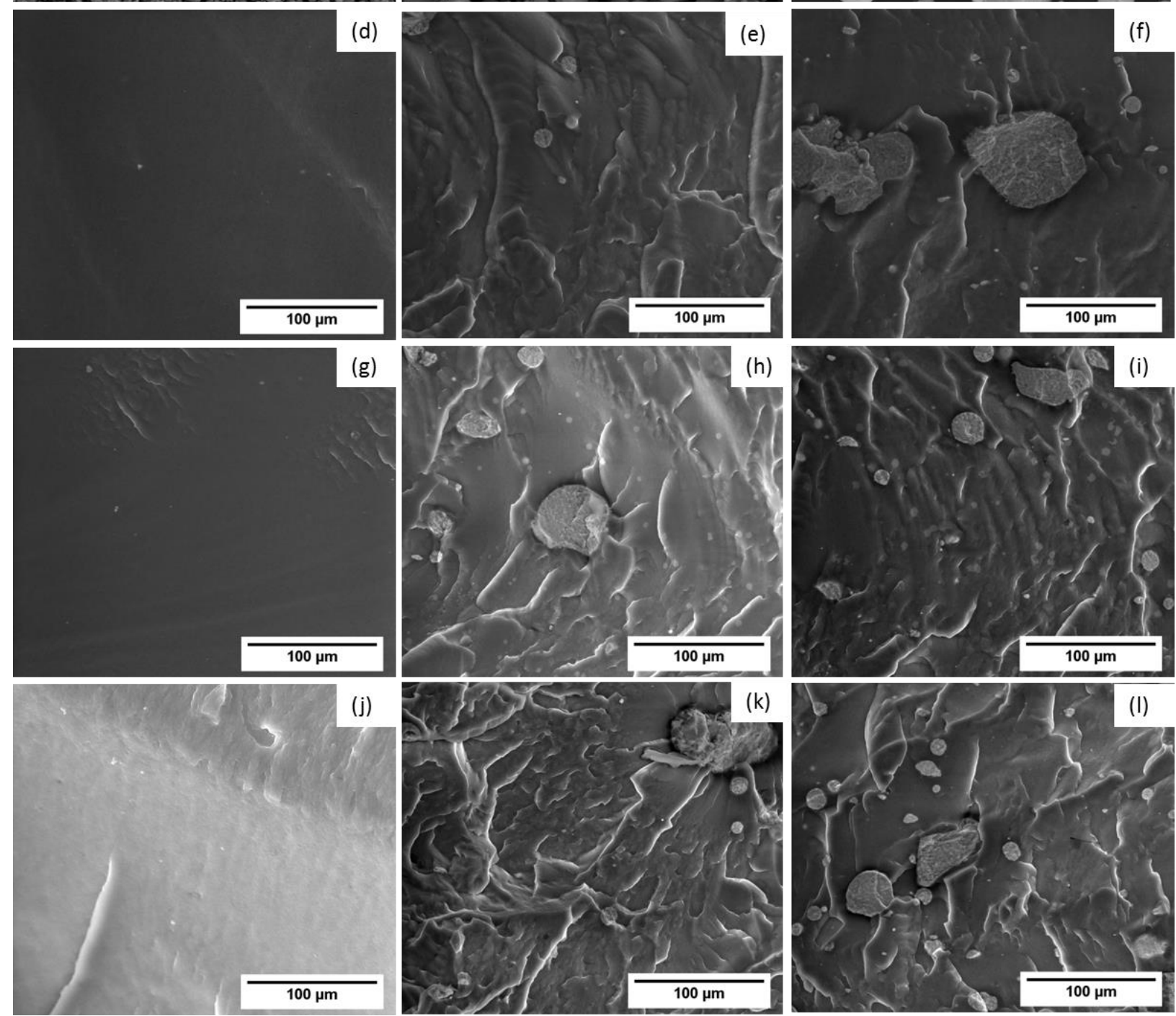

Figure 2. SEM images of: a, b - raw commercial barium titanate, c - surface treated commercial barium titanate, and d - S10B0, e - S10B5, f - S10B15, g - S15B0, h - S15B5, i - S15B15, j S30B0, k - S30B5, 1 - S30B15 in cryo-fractured cross-section surface. 


\subsection{Mechanical behavior}

Stress-strain curves were recorded (Figure 3a) at room temperature and atmospheric humidity.
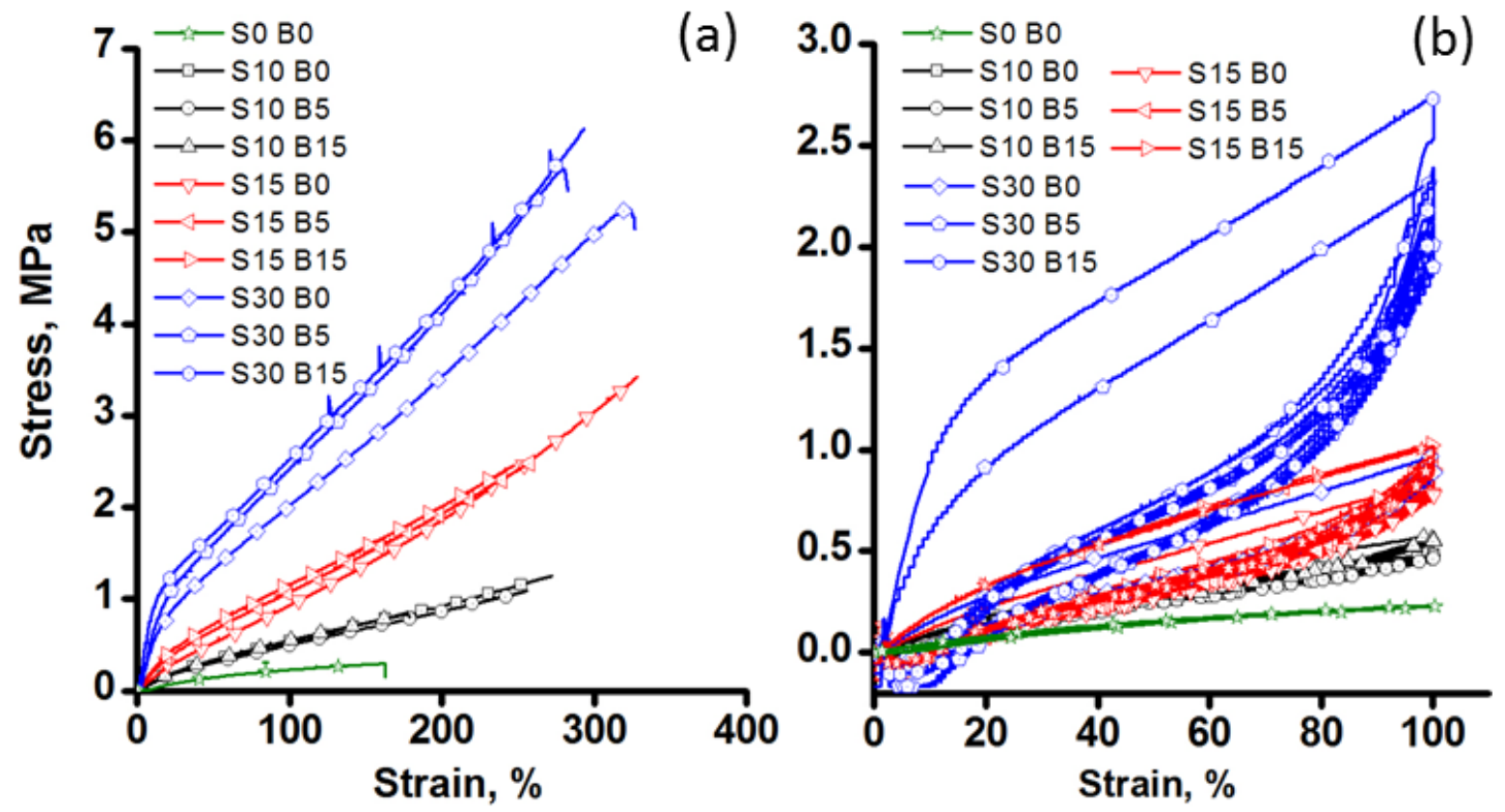

Figure 3. Normal (a) and cyclic (b) stress-strain curves recorded at RT and atmospheric humidity.

The main parameters estimated on the basis of these curves are centralized in Table 2. 


\begin{tabular}{|c|c|c|c|c|c|c|c|c|c|c|}
\hline Sample & $\begin{array}{l}d{ }^{\mathrm{a}} \\
\mathrm{mm}\end{array}$ & $\begin{array}{c}\sigma,{ }^{\mathrm{b}} \\
\mathrm{MPa}\end{array}$ & $\begin{array}{l}\overline{\varepsilon,} \\
\%\end{array}$ & $\begin{array}{l}\sigma_{\mathrm{el}}{ }^{\mathrm{d}} \\
\mathrm{MPa}\end{array}$ & $\begin{array}{c}\varepsilon_{\mathrm{el},}^{\mathrm{e}} \\
\%\end{array}$ & $\begin{array}{c}\mathbf{E}, \\
\text { MPa }\end{array}$ & $\varepsilon^{\prime g}$ & $\varepsilon^{\prime \prime h}$ & $\begin{array}{c}\mathbf{U v v}^{\mathbf{i}}{ }^{-} \\
\mathrm{v}\end{array}$ & $\begin{array}{l}\text { Uvv/d, } \\
\mathrm{V} \cdot \mathbf{m m}^{-1}\end{array}$ \\
\hline S0B0 & 1.60 & 0.15 & 162 & 0.1021 & 32.6 & 0.30 & 3.02 & 0.01 & 8 & 5.0 \\
\hline S10B0 & 0.88 & 1.25 & 272 & 0.1707 & 19.4 & 0.86 & 3.41 & 0.01 & 25 & 28.4 \\
\hline S10B5 & 0.89 & 1.09 & 255 & 0.0439 & 5.4 & 0.81 & 3.67 & 0.01 & 140 & 157.3 \\
\hline S10B15 & 0.91 & 0.81 & 178 & 0.1340 & 14.6 & 0.89 & 3.95 & 0.01 & 90 & 98.9 \\
\hline S15B0 & 0.84 & 3.41 & 328 & 0.2140 & 15.6 & 1.33 & 3.48 & 0.01 & 70 & 83.3 \\
\hline S15B5 & 0.91 & 2.50 & 259 & 0.2639 & 13.7 & 1.91 & 3.66 & 0.02 & 49 & 53.8 \\
\hline S15B15 & 0.96 & 2.45 & 247 & 0.2337 & 10.6 & 2.10 & 4.09 & 0.02 & 98 & 104.1 \\
\hline S30B0 & 0.82 & 5.03 & 326 & 0.5030 & 12.1 & 4.78 & 3.45 & 0.01 & 76 & 92.7 \\
\hline S30B5 & 1.01 & 5.44 & 282 & 0.7445 & 12.1 & 5.85 & 3.89 & 0.01 & 61 & 60.4 \\
\hline S30B15 & 0.93 & 6.13 & 292 & 0.9690 & 9.9 & 8.25 & 4.26 & 0.01 & 37 & 39.8 \\
\hline
\end{tabular}

${ }^{\mathrm{a}}$ Film thickness; ${ }^{\mathrm{b}}$ stress at break; ${ }^{\mathrm{c} e l o n g a t i o n}$ at break; ${ }^{\mathrm{d}}$ stress at the upper limit of elasticity;

${ }^{\mathrm{e}}$ strain at the upper limit of elasticity; 'Y Young's modulus (calculated at 15\% strain); ${ }^{\mathrm{g}}$ dielectric

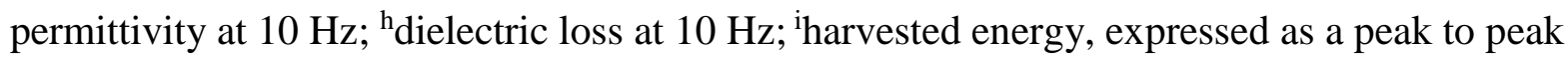
voltage; ${ }^{\mathrm{j}}$ harvested energy reported to the film thickness, expressed as a peak to peak voltage $/ \mathrm{mm}$.

Due to the compatibility and reinforcing effects of silica nanoparticles, the mechanical properties were enhanced as its incorporated amount rises. Thus, the ultimate tensile strength increases from 0.15 $\mathrm{MPa}$ for pure crosslinked silicone to 5.03 $\mathrm{MPa}$ when $30 \mathrm{wt} \%$ silica was incorporated (Table 2). However, the increase in elongation is modest one, from $162 \%$ for S0B0 to 272,328 and $326 \%$ for the elastomers containing 10, 15 and $30 \mathrm{wt} \% \mathrm{SiO}_{2}$, respectively. As a result, the 
Young's modulus significantly increased, from $0.30 \mathrm{MPa}$ for pure crosslinked silicone to 4.78 MPa for elastomer filled with $30 \mathrm{wt} \%$ silica. When the second filler, barium titanate, was added, due to its lower compatibility with silicone matrix and aggregates formation during the hydrophobization and incorporation procedures in polymeric matrix by mechanical mixing, a worsening is registered both in ultimate tensile stress and elongation values in the case of the series S10 and S15 containing less silica, while the Young's modulus continues to increase. This growth is not just of the same magnitude as that induced by incorporating increasing amounts of silica but generally occurs systematically in all three series, S10, S15, S30, as BT content increases from 0 to $15 \%$, from 0.86 to 0.89 , from 1.33 to 2.10 and from 4.78 to $8.25 \mathrm{MPa}$, respectively, as is suggested by graphical presentation in Figure 4.

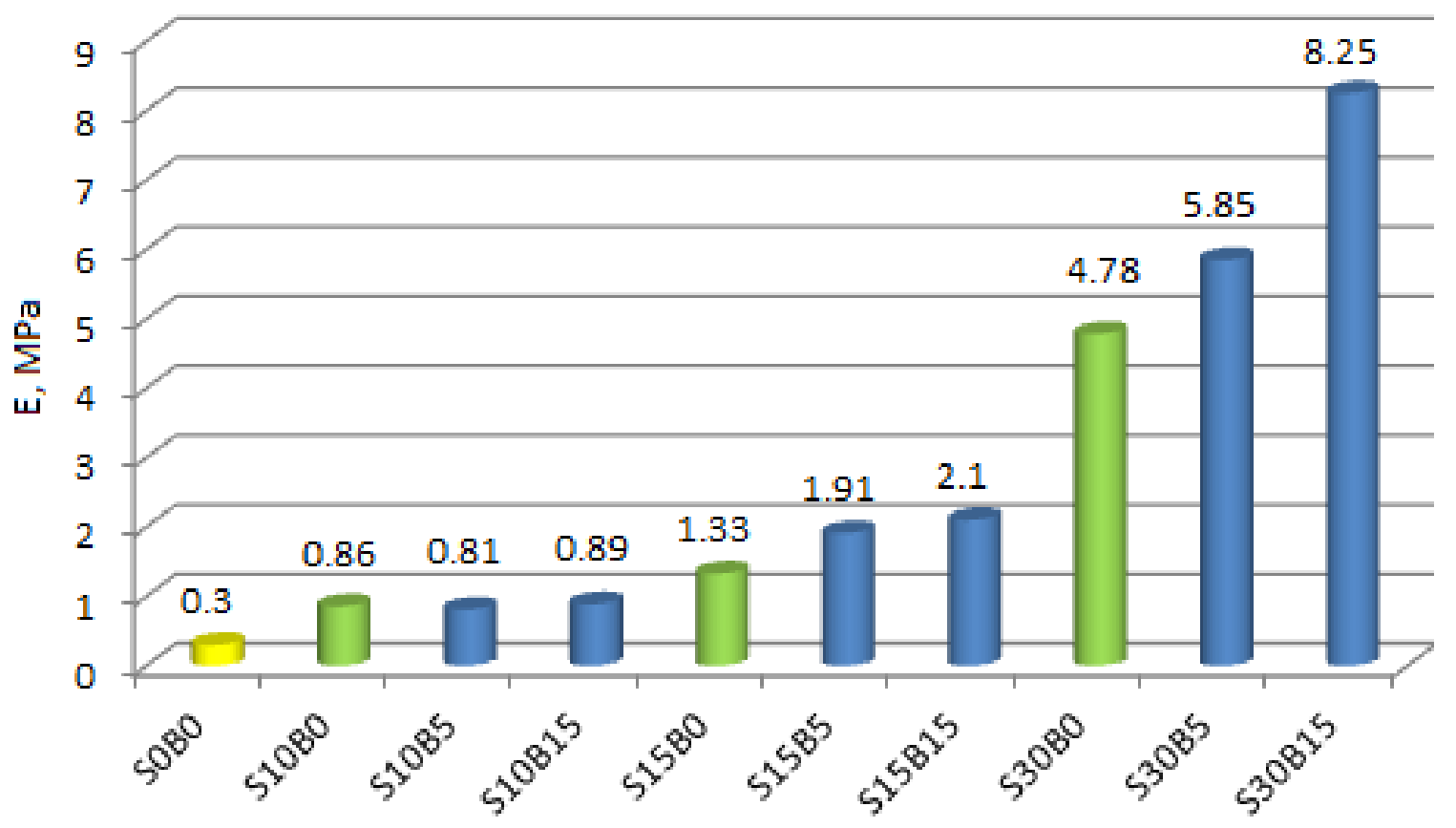

Figure 4. Evolution of elastic modulus (determined at 15\% strain) with the filler`s content. 
In order to evaluate mechanical fatigue resistance, cyclic stress-strain tests were performed, five cycles being made for each sample until $100 \%$ elongation from the initial length, at room temperature and atmospheric humidity (Figure 3b). After the first cycle, all samples show a big hysteresis loop which disappears, due to the rearrangements of polymeric chains when undergo elongation, also known as Mullins effect [35]. The shape of the cyclic stress-strain curves reveals that the incorporation of small percent of silica does not significantly affect the elastic properties of silicones. These are also not drastically affected by adding barium titanate to the composites containing 10 and $15 \mathrm{wt} \%$ silica. Instead, in the case of the composites containing $30 \mathrm{wt} \%$ silica and different percentages of barium titanate, the viscoelastic loss is manifested by the presence of visible hysteresis loops on the stress-strain curves. By the incorporation of the silica only (i.e., samples S10B0, S15B0, S30B0), the elastic region (where Hook's law can be applied) significantly decreases from $32.6 \%$ in pure crosslinked PDMS to $19.4,15.6$ and $12 \%$ when 10 , 15 and $30 \mathrm{wt} \%$ silica, respectively, was added (Table 2). This is a consequence of the limitations in the polymer chains movement due to the physical bond changes occurred within the strained material [36]. The contribution of the barium titanate to the viscoelastic loss is more reduced. The maximum limit of pure elastic strain decreases from 19.4 to 14.6 , from 15.6 to 10.6 and from 12.1 to $9.9 \%$, when $15 \mathrm{wt} \%$ barium titanate was incorporated into the samples of the three series, already containing 10,15 and $30 \%$ silica, respectively.

\subsection{Dielectric spectroscopy}

Dielectric spectra were also recorded at room temperature in the frequency range $1-10^{6} \mathrm{~Hz}$ (Figure 5) the desire being to have increased dielectric permittivity values while the dielectric 
loss to be at low level, which creates prerequisites for applying a low voltage for actuation or for more energy that could be harvested.

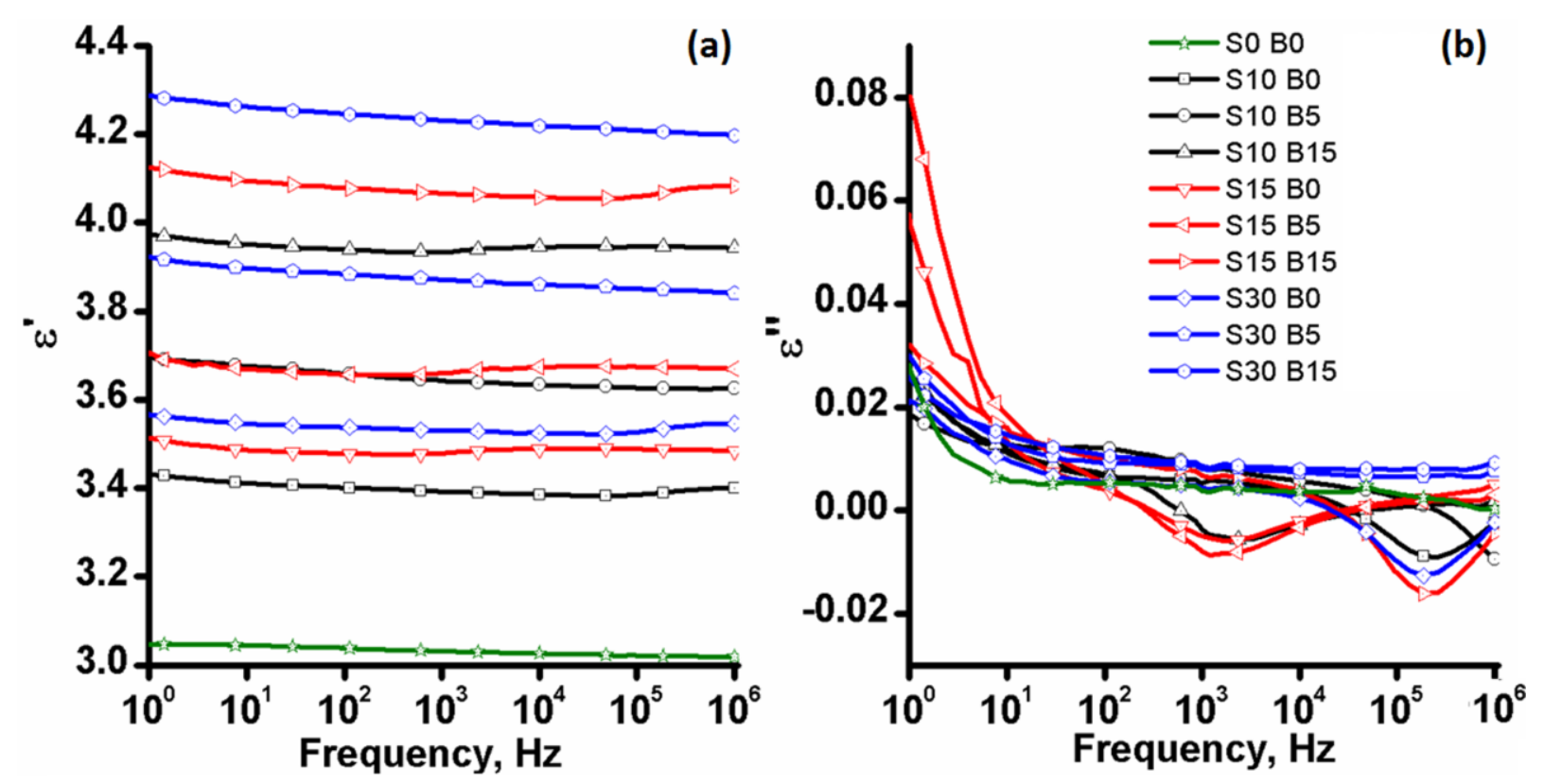

Figure 5. Dielectric measurements: (a) - Dielectric permittivity; (b) - Dielectric loss; the symbols have the same meaning for both graphs.

As can be seen, even adding silica only lead to a slight increase of the dielectric permittivity from 3.02 for pure matrix to $3.45,3.48$ by adding 15 and $30 \mathrm{wt} \%$ silica, respectively. When barium titanate was added, the dielectric permittivity increases as the filler content rises from 5 to $15 \mathrm{wt} \%$ (Table 2, Figure 6). The highest value, 4.26, was registered for the sample S30B15 with the highest amounts of the two fillers. 


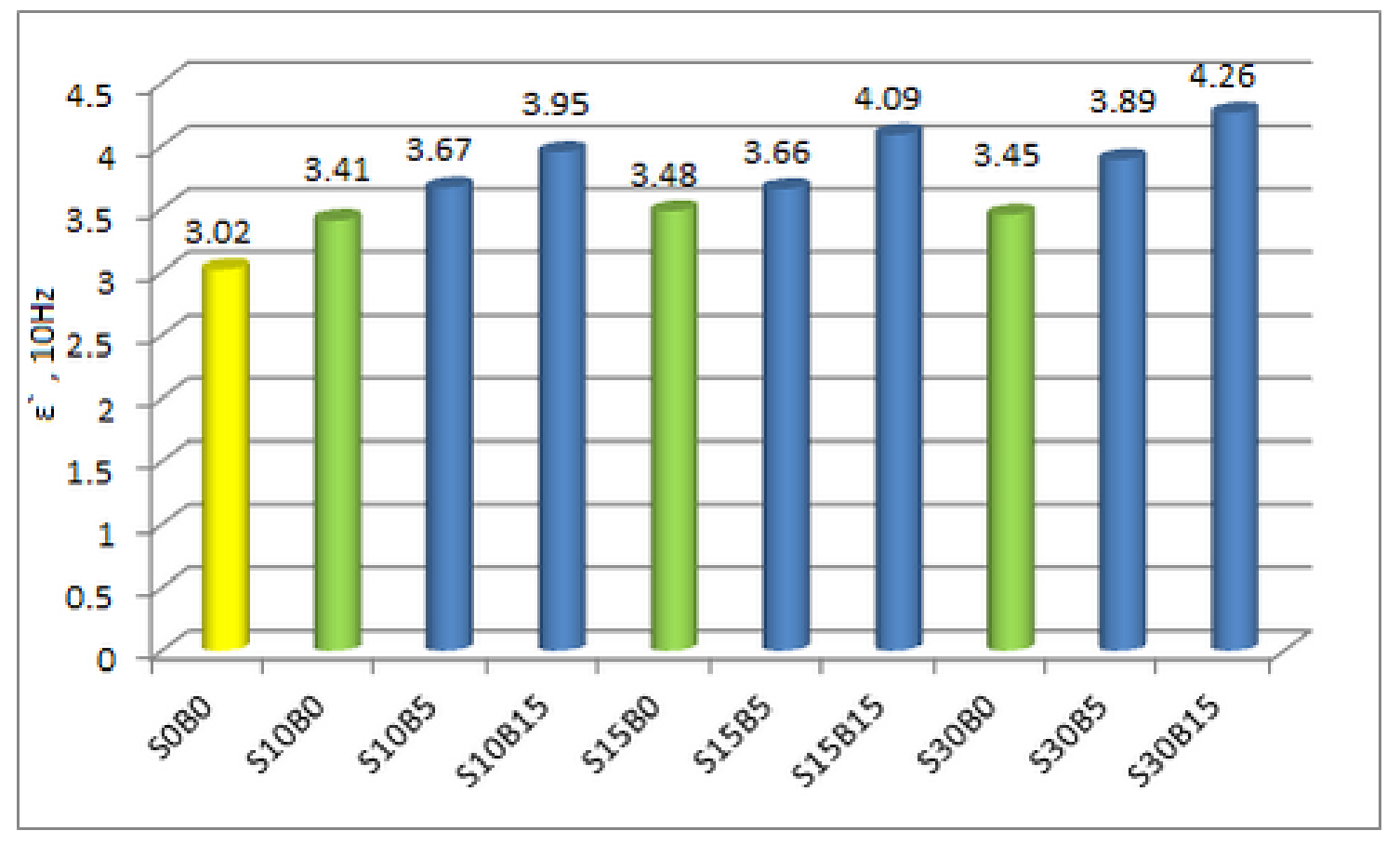

Figure 6. Comparative values of the dielectric permittivity at $10 \mathrm{~Hz}$ for the samples containing the two co-fillers in different ratios.

The increasing in the dielectric permittivity of the composite, as the amount of barium titanate added increases, is expected one at least from the perspective of volume-fraction average model:

$$
\varepsilon_{f f}=\varphi_{p} \varepsilon_{p}+\varphi_{c} \varepsilon_{c}+\varphi_{s} \varepsilon_{s}
$$

where the subscripts $\mathrm{p}, \mathrm{c}$ and $\mathrm{s}$ are the polymer, the ceramic phase and silica, respectively, and $\varphi$ is the volume fraction of the constituents. When an electric voltage is applied, positive and negative charges appear at the surface of the polar particles dispersed within continuous phase. Thus, the particles behave as dipoles, which align head-to-tail in the direction of the electric field and polarization leads to increased capability of the prepared dielectric materials to store energy [37]. Logic, increasing the volume fraction of the component with the highest dielectric constant $\left(\varepsilon_{\mathrm{BT}}^{\prime}=1700\right.$ at room temperature $)$, the dielectric permittivity of the composite should increase. However, the values obtained by this theoretical approach are more higher than experimental 
ones (Table 1S, Figure 2S). In fact the prediction of dielectric permittivity value by this way has been already disproved by other theoretical [38] and experimental studies [39]. Instead, the experimental values better fit theoretical ones obtained using other models, i.e., Maxwell-Garnett [40], Bruggeman [40, 41] and Lichtenecker-Rother [41-48] (see SI) as can be seen in Figure 7.

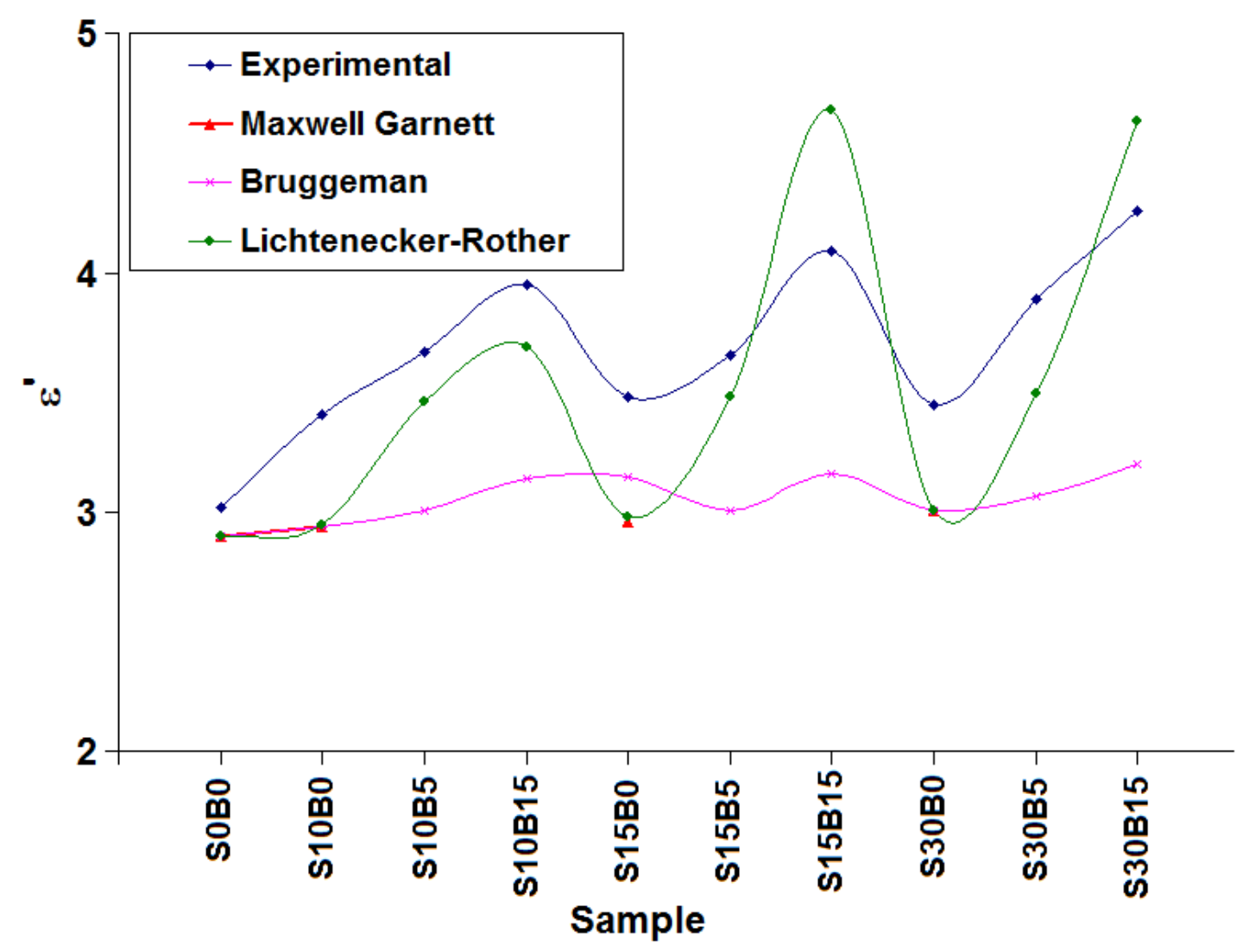

Figure 7. Plotting experimental dielectric permittivity values as compared with those theoretical estimated by using different models.

An interesting aspect is that, the dielectric permittivity remains almost stable over the entire range of frequencies. This might be ascribed to high stiffness matrix limiting pole orientation even at low frequencies. Dielectric loss values are low for all samples, thus the used fillers do not affect the insulating properties of PDMS based elastomers. The dropping below 0.00 value on 
some of dielectric loss curves recorded around $10^{3}$ and over $10^{5} \mathrm{~Hz}$ frequencies are due to resolution limits of the dielectric spectrometer.

\subsection{DSC analysis}

In order to see how the incorporation of the fillers affects the thermal transitions of the PDMS in composites, DSC curves were recorded in the range $-150 \ldots+50{ }^{\circ} \mathrm{C}$. It was observed (Figure $4 \mathrm{~S}$ ) that these do not vary significantly, only a few degrees with plus or minus from the reference sample values. Thus, the operating temperature window for composites do not change from that known for the silicones. Absolute heat capacity values determined on the basis of DSC curves (Figure 4S, Table 3) were used to estimate the crosslinking density according to procedure described in the literature [49-51]. The following equation was used:

$$
\rho_{\mathrm{c}}=\left(\mathrm{C}_{\mathrm{p}}{ }^{\mathrm{i}}-\mathrm{C}_{\mathrm{p}}{ }^{0}\right) / \mathrm{C}_{\mathrm{p}}^{0}
$$

with $C_{\mathrm{p}}^{\mathrm{i}}$ being the heat capacity of the polymer network at a given crosslinking density $[1,52]$ and $C^{0}$ the heat capacity of the non-crosslinked polymer. The heat capacity is a measure which energetically characterizes only segmental chain mobility in the polymer matrix.

Polydimethylsiloxanes have $T_{\mathrm{g}}$ around $-123^{\circ} \mathrm{C}$, while data from DSC analysis for the crosslinked samples show $T_{\mathrm{g}}$ values around this same temperature $\left(-123^{\circ} \mathrm{C}\right)$ (Figure $\left.3 \mathrm{~S}\right)$.

Therefore, the heat capacity for this transition is used for calculating the crosslinking density value, with equation (2), for each of the prepared samples, the results being centralized in Table 3. 
Table 3. Thermal and moisture sorption data

\begin{tabular}{|c|c|c|c|}
\hline \multirow[t]{4}{*}{ Sample } & \multicolumn{2}{|c|}{ DSC data } & \multirow[t]{4}{*}{ Weight, ${ }^{b} \%$ d.b. } \\
\hline & Heat capacity, a & Crosslinking & \\
\hline & $C_{\mathbf{p}}\left(\mathrm{J} \mathrm{g}^{-1} \mathbf{K}^{-1}\right)$ & density, & \\
\hline & & $\rho_{\mathrm{c}}^{\prime}\left(\mathbf{m o l} \mathbf{c m}^{-3}\right)$ & \\
\hline PDMS & 0.073 & - & - \\
\hline S0B0 & 0.097 & 0.328 & 0.57 \\
\hline S10B0 & 0.058 & 0.205 & 0.70 \\
\hline S10B5 & 0.061 & 0.164 & 0.36 \\
\hline S10B15 & 0.092 & 0.260 & 0.52 \\
\hline S15B0 & 0.091 & 0.246 & 0.66 \\
\hline S15B5 & 0.088 & 0.205 & 0.82 \\
\hline S15B15 & 0.052 & 0.287 & 0.33 \\
\hline S30B0 & 0.066 & 0.096 & 0.75 \\
\hline S30B5 & 0.087 & 0.191 & 0.89 \\
\hline S30B15 & 0.054 & 0.260 & 0.86 \\
\hline
\end{tabular}

${ }^{\mathrm{a}}$ Crosslinking density; ${ }^{\mathrm{b}}$ maximum vapour water sorption capacity reported to the dry mass.

The crosslinking degree decreases when silica particles are introduced in the composition of the silicone elastomers (from $0.328 \mathrm{~mol} \cdot \mathrm{cm}^{-3}$ for SOB0 to $0.196-0.246 \mathrm{~mol} \cdot \mathrm{cm}^{-3}$ by incorporating silica), and this leads to a small decrease of $\mathrm{T}_{\mathrm{g}}$, with $1-3^{\circ} \mathrm{C}$ in comparison with the pure crosslinked PDMS, S0B0. The surface of the silica particles is treated with octamethylcyclotetrasiloxane and therefore these particles are not acting as crosslinking centers but occupy the free volume between the siloxane polymer chains and interact with these only by physical interactions. However, the introduction of $15 \mathrm{wt} \%$ barium titanate nanoparticles in the formulation of the elastomers seems to lead to a small increase of crosslinking density $(0.260$, 
$0.287,0.260 \mathrm{~mol} \cdot \mathrm{cm}^{-3}$ for the samples $\mathrm{S} 10 \mathrm{~B} 15, \mathrm{~S} 15 \mathrm{~B} 15$ and $\mathrm{S} 30 \mathrm{~B} 15$, respectively) as compared with samples containing silica only, but not up to the level of pure siloxane polymer.

Unfortunately, it can not establish a correlation between the crosslinking degree and mechanical or dielectric characteristics due to the complexity of the material induced by the presence of the two fillers.

\subsection{Vapor sorption capacity}

The amount of humidity adsorbed by the dielectric can lead to failure when a voltage is applied; conductive pathways can form and dielectric breakdown suddenly appears. For this reason, the moisture behavior of the samples was investigated by recording water sorption isotherms at room temperature $\left(\sim 25^{\circ} \mathrm{C}\right)$ in the $0-90 \%$ relative humidity range (Figure $\left.3 \mathrm{~S}\right)$. The maximum sorption values range between 0.33 and $0.89 \mathrm{wt} \%$ indicating hydrophobic materials. A maximum sorption capacity of $0.57 \mathrm{wt} \%$ was recorded for the pure crosslinked silicone matrix while a very slight increase only can be noticed for some of the samples filled with silica $(0.7,0.66$, and $0.75 \mathrm{wt} \%)$ or silica and barium titanate (most of them around $0.8 \mathrm{wt} \%$ ) but without a logical variation. (Table 3).

\subsection{Energy harvesting measurements}

The capacity of the sample to convert the mechanical energy into electrical one, sought as a ultimate features, was estimated by using a set up similar to that described by us in ref. [11] and consisting in measuring peak to peak voltages generated by a mechanical impulse created by falling of a metal ball of $7.1 \mathrm{~g}$ from a height of $100 \mathrm{~mm}$ on the surface of the elastomeric films placed between two electrodes (Figure 8). 


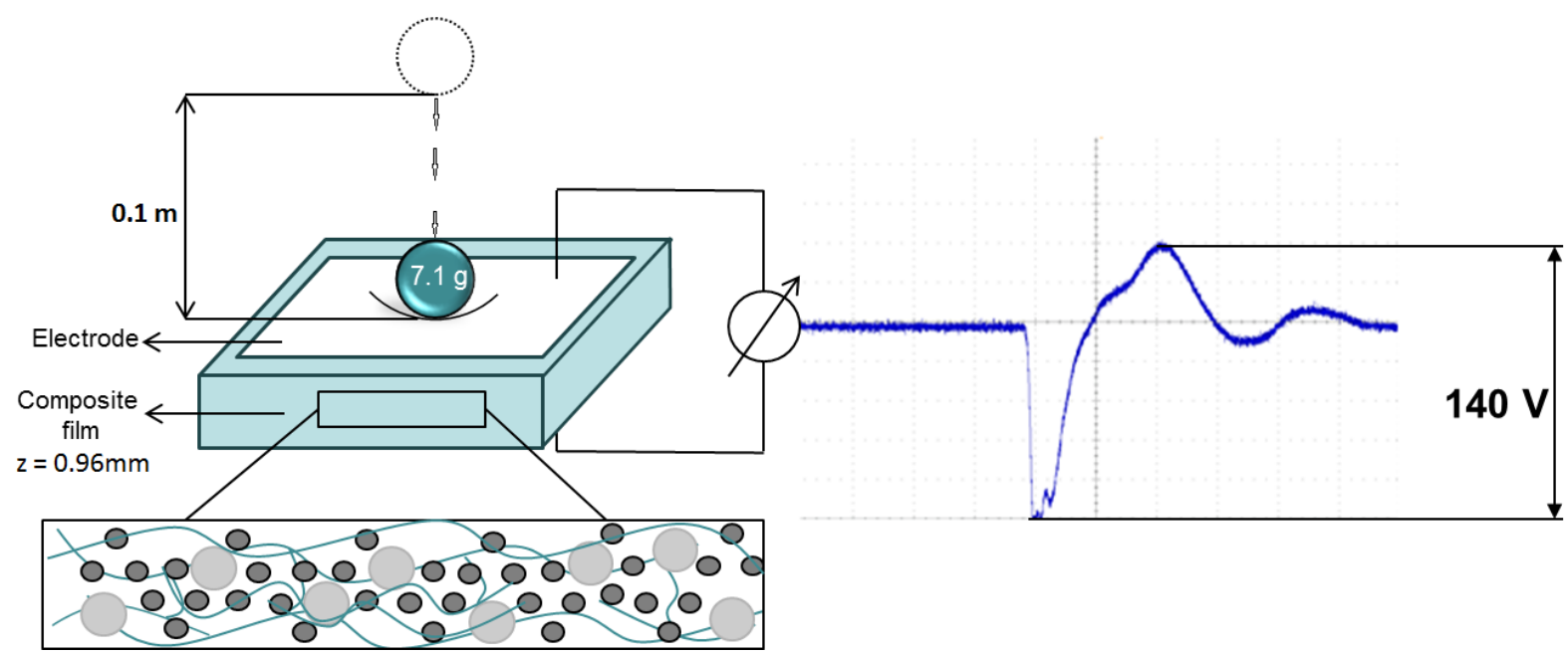

Figure 8. Setup for the energy harvesting measurements and an illustrative signal registered for the sample S10B5 (See Figure 5S for the other samples).

The dynamic parameters used for these experiments were:

- $\quad$ speed at contact with the elastomeric membrane, $v$ :

$$
v=\sqrt{2 g h}=\sqrt{2 \cdot 9.8 \cdot 0.1}=1.4[\mathrm{~m} / \mathrm{s}]
$$

- mechanical impulse, $p$ :

$$
p=m v=9.94 \cdot 10^{-3}[N s]
$$

- $\quad$ kinetic energy in contact, $E$ :

$$
E=\frac{m v^{2}}{2}=6.96 \cdot 10^{-3}[J]
$$

- $\quad$ the micro-force, $F$ :

$$
F=\frac{E}{h}=0.0696[N]
$$


Compared with existing results [29, 53-55], the amounts of energy harvested, expressed as a peak to peak voltage for all samples (Table 2), indicate good values ranging between 25 and 140 V. As films of different thicknesses were measured, the peak to peak voltages have been reported to the film thickness in order to better compare the samples to each other. It seems like, along with dielectric permittivity value induced by the silica and barium titanate content, Young's modulus has a great influence. Thus, sample S10B5 (10 wt $\%$ silica and $5 \mathrm{wt} \%$ barium titanate) having the lowest value for Young's modulus ( $0.81 \mathrm{MPa})$ among all composites showed the biggest harvested energy value, $157.3 \mathrm{~V} / \mathrm{mm}$, although the dielectric permittivity is 3.67 only.

\section{Conclusions}

A series of silicone elastomer samples have been prepared by incorporation of two fillers, silica and barium titanate, each of them having different roles, within a high molecular mass polydimethylsiloxane- $\alpha, \omega$-diol followed by a peroxide crosslinking. By incorporating silica, Young`s modulus strongly increased, as expected, but there was also a very slightly increasing in the dielectric permittivity value. Instead, by the addition of the second filler, barium titanate, while the dielectric permittivity more significantly increases, as expected, reaching 4.28 value (at $15 \mathrm{wt} \%$ barium titanate and $30 \mathrm{wt} \%$ silica loading), and the obtained values reasonably fit those estimated on the basis of several theoretical models, a worsening is registered both in tensile stress and elongation values in the series with less silica (S10 and S15), due to lower compatibility of ceramic filler with silicone matrix and the aggregates formation. Cyclic stressstrain tests revealed that the elastic properties of resulted elastomers are not significantly affected by incorporation of barium titanate but they are rather influenced by the silica content. The dielectric permittivities of all prepared samples remain almost stable over the entire range of 
frequencies. Dielectric loss values are low for all samples. The incorporation of the silica and barium titanate not significantly affects the thermal transitions and moisture sorption of the composites. Instead, by incorporating silica, the crosslinking degree decreases as was estimated on the basis of DSC curves, while by co-adding barium titanate some of this loss is recovered but not to the level found in pure crosslinked silicones. The preliminary harvesting tests reveal promising results, the best value, $157 \mathrm{~V} / \mathrm{mm}$, being obtained in the case of the sample, which has lowest Young's modulus among prepared composites, $0.81 \mathrm{MPa}$ and dielectric permittivity 3.67. Thus, starting from the chosen polymer matrix and crosslinking system and considering output energy as an ultimate features sought, the optimum formulation seems to be S10B5, filled with $10 \mathrm{wt} \%$ silica and $5 \mathrm{wt} \%$ barium titanate.

Supporting Information: Figures 1S shows film formation procedure; Figure 2S- Plotting experimental dielectric permittivity values as compared with those theoretical estimated by using different models; Figure 3S - DSC curves for all samples; Figure 4S- water vapor sorption isotherms; Figure 5S - The electric responses at an applied mechanical impulse; Table 1SDielectric permittivity values predicted by using different models; Theoretical estimation of dielectric permittivity. This material is available free of charge via the Internet at http://pubs.acs.org.

Acknowledgements: The work presented in this paper is developed in the context of the project PolyWEC (www.polywec.org, prj. ref. 309139), a FET-Energy project that is partially funded by the $7^{\text {th }}$ Framework Programme of European Community and co-financed by Romanian National Authority for Scientific Research, CNCS-UEFISCDI (Contract 205EU). One of the authors (C.- 
D. Varganici) acknowledges the financial support of a grant of the Romanian National Authority

for Scientific Research, CNCS-UEFISCDI, project number PN-II-ID-PCCE-2011-2-0028.

\section{References}

1. Lin Z-H, Yang Y, Wu JM, et al. (2012) BaTiO 3 Nanotubes-Based Flexible and Transparent Nanogenerators. J Phys Chem Lett 3:3599-3604. doi: 10.1021/jz301805f

2. Park K Il, Xu S, Liu Y, et al. (2010) Piezoelectric BaTiO3 thin film nanogenerator on plastic substrates. Nano Lett 10:4939-4943. doi: 10.1021/nl102959k

3. Maas J, Graf C (2012) Dielectric elastomers for hydro power harvesting. Smart Mater Struct 21:064006. doi: 10.1088/0964-1726/21/6/064006

4. Pelrine R, Kornbluh R, Joseph J, et al. (2000) High-field deformation of elastomeric dielectrics for actuators. Mater Sci Eng C 11:89-100. doi: 10.1016/S0928-4931(00)001284

5. Carpi F, De Rossi D, Kornbluh R, Pelrine R, Sommer-Larsen P (2008) Dielectric Elastomers as Electromechanical Transducers: Fundamentals, Materials, Devices, Models and Applications of an emerging electroactive Polymer Technology, Elsevier Ltd.

6. Sabourin CL, Carpenter JC, Leib TK, Spivack JL (1996) Biodegradation of dimethylsilanediol in soils. Appl Environ Microbiol 62:4352-60.

7. Chandrasekhar V (2005) Inorganic and organometallic polymers. Inorg Organomet Polym 13:1-339. doi: 10.1007/b137079

8. Mark J (1999) Polymer Data Handbook. New York, USA 1274. doi: 10.1021/ja907879q

9. Gallone G, Carpi F, Galantini F, De Rossi D, (2008) Enhancing the dielectric permittivity of elastomers. In: Carpi F, De Rossi D, Kornbluh R, Pelrine R, Sommer-Larsen P (eds) Dielectric Elastomers as Electromechanical Transducers: Fundamentals, Materials, Devices, Models and Applications of an emerging electroactive Polymer Technology, Elsevier Ltd.

10. Nelson JK, Linhardt RJ, Schadler LS, Hillborg H (2012) Effect of high aspect ratio filler on dielectric properties of polymer composites: a study on barium titanate fibers and graphene platelets. IEEE Trans Dielectr Electr Insul 19:960-967. doi:

10.1109/TDEI.2012.6215100 
11. Cazacu M, Ignat M, Racles C, et al. (2013) Well-defined silicone-titania composites with good performances in actuation and energy harvesting. J Compos Mater 48:1533-1545. doi: $10.1177 / 0021998313488148$

12. Romasanta LJ, Leret P, Casaban L, et al. (2012) Towards materials with enhanced electromechanical response: $\mathrm{CaCu} 3 \mathrm{Ti} 4 \mathrm{O} 12-$ polydimethylsiloxane composites. J Mater Chem 22:24705. doi: 10.1039/c2jm34674e

13. Molberg M, Walder C, Opris D, et al. (2009) Frequency-dependent dielectric and mechanical behavior of elastomers for actuator applications. EMPA Act 20. doi: $10.1063 / 1.3211957$

14. Khastgir D, Adachi K (2000) Rheological and dielectric studies of aggregation of barium titanate particles suspended in polydimethylsiloxane. Polymer (Guildf) 41:6403-6413. doi: 10.1016/S0032-3861(99)00840-X

15. Kapustianyk V, Shchur Y, Kityk I, et al. (2008) nanocrystals incorporated into the PMMA matrix. J Phys Condens Matter 20:365215. doi: 10.1088/0953-8984/20/36/365215

16. Lach G, Laskowski L, Kityk I V., et al. (2007) Dielectric relaxation of (N(C2H5)4)2CoCl2Br2 nanocrystallites incorporated into the PMMA matrix. J Non Cryst Solids 353:4353-4356. doi: 10.1016/j.jnoncrysol.2007.01.081

17. Cheng K-C, Lin C-M, Wang S-F, et al. (2007) Dielectric properties of epoxy resin-barium titanate composites at high frequency. Mater Lett 61:757-760. doi: 10.1016/j.matlet.2006.05.061

18. Li YC, Tjong SC, Li RKY (2011) Dielectric properties of binary polyvinylidene fluoride/barium titanate nanocomposites and their nanographite doped hybrids. xPRESSS Polym Lett 5:526-534

19. Hanemann T, Schumacher B (2012) Realization of embedded capacitors using polymer matrix composites with barium titanate as high-k-active filler. Microsyst Technol 18:745751. doi: 10.1007/s00542-012-1458-4

20. Chon J, Ye S, Cha KJ, et al. (2010) High-dielectric sol-gel hybrid materials containing barium titanate nanoparticles. Chem Mater 22:5445-5452. doi: 10.1021/cm100729d

21. Nayak S, Kumar Chaki T, Khastgir D (2012) Development of Poly(dimethylsiloxane)/ $/ \mathrm{BaTiO}_{3}$ Nanocomposites as Dielectric Material. Adv Mater Res 622-623:897-900. doi: 10.4028/www.scientific.net/AMR.622-623.897

22. Nayak S, Chaki TK, Khastgir D (2014) Development of Flexible Piezoelectric Poly ( dimethylsiloxane ) - BaTiO 3 Nanocomposites for Electrical Energy Harvesting. Ind. Eng Chem Res 53:14982-14992 
23. Polymeric Materials Encyclopedia, Twelve Volume Set - AbeBooks - Salamone, Joseph C.: 084932470X. http://www.abebooks.com/9780849324703/Polymeric-MaterialsEncyclopedia-Twelve-Volume-084932470X/plp. Accessed 20 Jan 2015

24. Warrick EL, Pierce OR, Polmanteer KE, Saam JC (1979) Silicone Elastomer Developments 1967-1977. Rubber Chem Technol 52:437-525. doi: 10.5254/1.3535229

25. Bele A, Cazacu M, Stiubianu G, Vlad S (2014) RSC Advances Silicone - barium titanate composites with increased electromechanical sensitivity. The effects of fillers morphology. RSC Adv 4:58522-58529. doi: 10.1039/C4RA09903F

26. Bele A, Cazacu M, Stiubianu G, et al. (2015) Composites : Part B Polydimethylsiloxane barium titanate composites : Preparation and evaluation of the morphology, moisture, thermal , mechanical and dielectric behavior. Compos PART B 68:237-245. doi: 10.1016/j.compositesb.2014.08.050

27. Racles C, Cazacu M, Fischer B, Opris DM (2013) Synthesis and characterization of silicones containing cyanopropyl groups and their use in dielectric elastomer actuators. Smart Mater Struct 22:104004. doi: 10.1088/0964-1726/22/10/104004

28. Cazacu M, Racles C, Zaltariov M-F, et al. (2013) Electroactive composites based on polydimethylsiloxane and some new metal complexes. Smart Mater Struct 22:104008. doi: 10.1088/0964-1726/22/10/104008

29. Liu Y, Liu L, Zhang Z, et al. (2010) Analysis and manufacture of an energy harvester based on a Mooney-Rivlin-type dielectric elastomer. EPL Europhysics Lett 90:36004. doi: 10.1209/0295-5075/90/36004

30. Alexandru M, Cazacu M, Nistor A, Musteata VE, Stoica I, Grigoras C, Simionescu B.C (2010) Polydimethylsiloxane/silica/titania composites preparedby solvent-free sol-gel technique, J Sol-Gel Sci Technol 56:310-319.

31. Biggs J, Danielmeier K, Hitzbleck J, et al. (2013) Electroactive polymers: Developments of and perspectives for dielectric elastomers. Angew Chemie - Int Ed 52:9409-9421. doi: 10.1002/anie.201301918

32. Madsen FB, Yu L, Daugaard a. E, et al. (2015) A new soft dielectric silicone elastomer matrix with high mechanical integrity and low losses. RSC Adv 5:10254-10259. doi: 10.1039/C4RA13511C

33. Cazacu M, Racles C, Vlad A, et al. (2009) Silicone-based Composite for Relining of Removable Dental Prosthesis. J Compos Mater 43:2045-2055. doi: $10.1177 / 0021998309340447$

34. Freeman G (1962) Silicones : An Introduction tso their Chemistry and Applications. Iliffe Book Limited 
35. Diani J, Fayolle B, Gilormini P (2009) A review on the Mullins effect. Eur Polym J 45:601-612. doi: 10.1016/j.eurpolymj.2008.11.017

36. Mallinson LG (2001) Ageing Studies and Lifetime Extension of Materials. doi: 10.1007/978-1-4615-1215-8

37. Lu J, Wong CP (2008) Nanoparticle-Based High- $k$ Dielectric Composites: Opportunities and Challenges. In: J.E. Morris (ed.) Nanopackaging: Nanotechnologies and Electronics Packaging. Springer Science + Business Media, LLC, pp. 121-137

38. Ying KL, Hsieh TE (2007) Sintering behaviors and dielectric properties of nanocrystalline barium titanate. Mater Sci Eng B Solid-State Mater Adv Technol 138:241-245. doi: 10.1016/j.mseb.2007.01.002

39. Brosseau C (2006) Modelling and simulation of dielectric heterostructures: a physical survey from an historical perspective. J Phys D Appl Phys 39:1277-1294. doi: $10.1088 / 0022-3727 / 39 / 7 / \mathrm{S} 02$

40. Yoon DH, Zhang J, Lee BI (2003) Dielectric constant and mixing model of BaTiO3 composite thick films. Mater Res Bull 38:765-772. doi: 10.1016/S0025-5408(03)00075-8

41. Bosch S, Ferré-Borrull J, Leinfellner N, Canillas A (2000) Effective dielectric function of mixtures of three or more materials: a numerical procedure for computations. Surf Sci 453:9-17. doi: 10.1016/S0039-6028(00)00354-X

42. Lichtenecker K, Rother K (1931) Die Herleitung des logarithmischen Mischungsgesetz es aus allgemeinen Prinzipien der stationären Strömung. Physikalische Zeitschrift 32:255260

43. Nelson SO (1983) Observations on the Density Dependence of Dielectric Properties of Particulate Materials. J. Microw. Power 18:143-152

44. Landau L, Lifshitz E (1984.) Electrodynamics of Continuous Media 2nd edn. Pergamon Press, New York

45. Looyenga H (1965) Dielectric constants of heterogeneous mixtures. Physica 31:401-406. doi: 10.1016/0031-8914(65)90045-5

46. Karkkainen KK (2000) Effective permittivity of mixtures: numerical validation by the FDTD method. IEEE Trans Geosci Remote Sens 38:1303-1308. doi: 10.1109/36.843023

47. Brosseau C, Quéffélec P, Talbot P (2001) Microwave characterization of filled polymers. J Appl Phys 89:4532-4540. doi: 10.1063/1.1343521

48. Gershon D, Calame JP, Birnboim a. (2001) Complex permittivity measurements and mixings laws of alumina composites. J Appl Phys 89:8110-8116. doi: 10.1063/1.1369400 
49. Varganici C-D, Ursache O, Gaina C, et al. (2012) Studies on new hybrid materials prepared by both Diels-Alder and Michael addition reactions. J Therm Anal Calorim 1561-1570. doi: 10.1007/s10973-012-2532-y

50. Varganici CD, Rosu L, Rosu D, Simionescu BC (2013) Miscibility studies of some semiinterpenetrating polymer networks based on an aromatic polyurethane and epoxy resin. Compos Part B Eng 50:273-278. doi: 10.1016/j.compositesb.2013.02.005

51. Vera-Graziano R, Hernandez-Sanchez F, Cauich-Rodriguez J V. (1995) Study of crosslinking density in polydimethylsiloxane networks by DSC. J Appl Polym Sci 55:1317-1327. doi: 10.1002/app.1995.070550905

52. Flory PJ, Rehner J (1943) Statistical Mechanics of Cross-Linked Polymer Networks II. Swelling. J Chem Phys 11:521. doi: 10.1063/1.1723792

53. Yang G, Ren W, Mukherjee BK, et al. (2006) Transverse Strain Response of Silicone Dielectric Elastomer Actuators. Polymer. J Adv Sci 18:166-169. doi: 10.2978/jsas.18.166

54. Granstrom J, Feenstra J, Sodano HA, Farinholt K (2007) Energy harvesting from a backpack instrumented with piezoelectric shoulder straps. Smart Mater Struct 16:1810 1820. doi: 10.1088/0964-1726/16/5/036

55. Kwon D, Rincon-Mora GA (2009) A rectifier-free piezoelectric energy harvester circuit. In: 2009 IEEE Int. Symp. Circuits Syst. IEEE, pp 1085-1088 
Click here to download Supplementary Material: Supporting Information-r.docx 